\title{
Female Sexual Dysfunction among Chinese Primiparous Women
}

\author{
Wenying Li1 ${ }^{*}$, Tippawan Liabsuetrakul², Babill Stray-Pedersen ${ }^{3}$ \\ ${ }^{1}$ Department of Obstetrics and Gynecology, Aviation General Hospital, Beijing, China \\ ${ }^{2}$ Epidemiology Unit, Faculty of Medicine, Prince of Songkla University, Songkhla, Thailand \\ ${ }^{3}$ Department of Women, Rikshospitalet, Oslo University Hospital and University of Oslo, Oslo, Norway \\ Email: *muziwen9999@163.com, ${ }^{\star}$ muziwen9999@hotmail.com
}

How to cite this paper: Li, W.Y., Liabsuetrakul, T. and Stray-Pedersen, B. (2017) Female Sexual Dysfunction among Chinese Primiparous Women. Open Journal of Obstetrics and Gynecology, 7, 1282-1291. https://doi.org/10.4236/ojog.2017.713131

Received: November 21, 2017

Accepted: December 19, 2017

Published: December 22, 2017

Copyright $\odot 2017$ by authors and Scientific Research Publishing Inc. This work is licensed under the Creative Commons Attribution International License (CC BY 4.0).

http://creativecommons.org/licenses/by/4.0/ (c) (i) Open Access

\begin{abstract}
Objective: To compare sexual function between primiparous women who underwent cesarean section (CS) and those who delivered vaginally. Methods. This cross-sectional study was conducted from October 2011 to April 2012 in Beijing, China. The target population included women aged 18 - 45 years who had given birth only once at least 6 months prior. The questionnaire was self-administered including female sexual function measured using the $\mathrm{Fe}$ male Sexual Function Index (FSFI). Data were analyzed using R software with the significance level of 0.05 . Results: A total of 1456 participants were included and 102 women $(7.0 \%)$ declined. The median age of the participants was 35 years. The median time interval after childbirth was 6 years. The median FSFI score was 26.9 and prevalence of female sexual dysfunction (FSD) was $34.2 \%$. Both the FSFI scores and the proportions of individuals with sexual disorders were similar between women undergoing CS and those having vaginal delivery for both individual domains and the full scale. Conclusion: There were insignificant differences in female sexual function scores and FSD prevalence between women undergoing CS versus vaginal delivery.
\end{abstract}

\section{Keywords}

Cesarean Section, Female Sexual Dysfunction, Female Sexual Function Index, Mode of Delivery

\section{Introduction}

Sexual health is defined as "a state of physical, emotional, mental, and social well-being in relation to sexuality" [1]. Evaluation of female sexual dysfunction (FSD), defined as disorders of sexual desire, arousal, orgasm, and sexual pain, 
was recommended by an international consensus when assessing female sexual health [2]. According to a large population-based survey of women in the USA, the prevalence of any self-reported sexual problem (related to desire, arousal, or orgasm) and sexually related personal distress was $43.1 \%$ and $22.2 \%$ for the total population and $27.2 \%$ and $24.4 \%$ for reproductive-aged women, respectively [3]. Almost two-thirds of women (64.3\%) reported that they had experienced sexual dysfunction during the first year after childbirth, and almost three-quarters (70.5\%) reported they experienced sexual dissatisfaction. The most prevalent types of sexual dysfunction reported were sexual desire disorder (81.2\%), problems achieving orgasm (53.5\%), and sexual arousal disorder (52.3\%) [4].

In addition to its high prevalence, FSD after childbirth is a concern due to the increasing cesarean rate and the perceived benefits of cesarean section (CS) on female sexual function held by both health care providers and women giving birth [5]. As FSD is a multi-dimensional and sensitive disorder, it should be measured using a well-developed, standardized, and validated instrument that can cover each of its aspects [6]. The association between mode of delivery and sexual problems has been assessed by limited studies using validated questionnaires, and the evidence has been conflicting. Some studies have shown no significant association between mode of delivery and sexual function [7] [8] [9], whereas Baksu et al. found that sexual function score was lower at six months postpartum among primiparous women who underwent vaginal delivery compared to those who underwent CS [10]. Interestingly, a study conducted in Japan reported that CS affected sexual health more than vaginal delivery without laceration [11].

Among the few available studies using validated questionnaires, mixed parity, small sample size and short-term post-delivery follow-up were the major limitations [7] [8] [9] [10] [11]. Therefore, the objective of the current study was to compare sexual function between primiparous women who underwent CS and those who delivered vaginally over a wide time range after childbirth.

\section{Materials and Methods}

This cross-sectional study is part of a research on the relationship between physical and sexual health and different modes of delivery. The study was conducted from October 2011 to April 2012. The target population included women aged 18 - 45 years who had given birth only once at least 6 months prior. The sample size calculation was documented in detail in a prior report [12]. In brief, a difference of $15 \%$ was adopted for the prevalence of non-cyclic pelvic pain between women with a cesarean delivery and those with a vaginal delivery according to reference retrieval. Given the study power of $80 \%$, a sample size of at least 300 primiparas ( 150 per mode of delivery) was needed, assuming a ratio of cesarean to vaginal delivery of 1 . Considering a wide time range after birth, 4 times of primiparas were recruited. Allowing for $10 \%$ incomplete data, nearly 1350 primiparas were required [12]. The questionnaire was self-administered and re- 
quired approximately 30 - 40 minutes to complete.

Female sexual function was measured using the Female Sexual Function Index (FSFI), which is a validated 19-item questionnaire with 6 domains consisting of desire, arousal, lubrication, orgasm, satisfaction and pain during sexual intercourse based on sexual response cycle. For each item, the response spans 5 - 6 levels with different domain factors, thus creating a full-scale score ranging from 2 to 36 [6]. A full FSFI score of less than 25 was used to represent FSD, and a score less than the median value was considered to represent sexual dysfunction in each domain [13]. Therefore, a desire score $<3.6$ (range $1.2-6$ ), an arousal score $<3.0$ (range $0-6$ ), a lubrication score $<3.0$ (range $0-6$ ), an orgasm score $<3.0$ (range $0-6$ ), a satisfaction score $<3.4$ (range $0.8-6$ ) and a pain score $<3.0$ (range 0 - 6) were adopted as cut-offs.

Independent variables included mode of delivery, age, body mass index (BMI) [14], education, monthly household income, marital status, couple relationship, chronic medical disease, and current depression. The parameter of couple relationship represented women's attitudes towards their couple relationships measured using a seven-point bipolar adjective dimension from the Semantic Differential Osgood scale that ranged from "very unhappy" to "very happy". The seven-point scale was dichotomized as "negative" (scale of 4 or less) and "positive" (scale of 5 or more). The cut-off point for income was 900USD, which represents twice the average income per capita in Beijing in 2011 [15]. Chronic medical diseases included hypertension, diabetes, hyperlipidemia, and endocrine disease requiring medication or medical consultation. Current depression was defined as a score of 10 or more on the validated Chinese version of the Edinburg Postnatal Depression Scale (EPDS) questionnaire [16].

Data were recorded in Epidata (version 3.1) and analyzed using $\mathrm{R}$ software (version 3.2.3, The R Foundation for Statistical Computing, Vienna, Austria 2015). Univariate analysis for FSD was performed using the chi-squared test for categorical variables and the Wilcoxon rank sum test for continuous variables. Variables with a $\mathrm{P}$-value of less than 0.2 were included in a logistic regression model for FSD. The significance level was 0.05 .

This study was approved by the Ethical Committee of the Faculty of Medicine, Prince of Songkla University, Songkhla, Thailand and the Ethical Committee of First Hospital of Tsinghua University, Beijing, China. All participants were provided with information regarding the study and gave written informed consent prior to data collection.

\section{Results}

A total of 1456 participants were included. Female sexual function was measured using the FSFI instrument; 102 women (7.0\%) declined. Non-response was more common among unmarried women $(\mathrm{P}<0.001)$ and those with a high/technical school education $(\mathrm{P}=0.01)$. The median age of the participants was 35 years (range: 20 - 45 years). The median time interval after childbirth was 6 years 
(range: 6 months to 22 years).

The FSFI scores and prevalence of FSD (less than the median value for an individual domain and less than 25 for the full scale) are shown in Table 1 . The median FSFI score was lower in desire (3.0, IQR 2.4, 3.6) and arousal (3.9, IQR $3.3,4.5)$ domain, while higher in the lubrication (5.1, IQR 4.2, 5.7) and pain (6.0, IQR 4.8, 6.0) domain. Disorders in individual sexual function domains varied greatly, from $10.5 \%$ for pain to $19.6 \%$ for arousal and to $67.2 \%$ for desire. The prevalence of FSD using the full scale was $34.2 \%$.

A comparison of the characteristics of the women with and without FSD is shown in Table 2. The female sexual function was not associated with women's age $(p=0.13)$, education $(p=0.66)$, marital status $(p=0.17)$, and mode of delivery $(p=0.79)$; however, it was related to the primipara's BMI $(p=0.004)$, family monthly income $(\mathrm{p}=0.006)$, relationship with partner $(\mathrm{p}<0.001)$, having medical comorbidity $(\mathrm{p}=0.001)$ and current depression $(\mathrm{p}<0.001)$. After logistic regression analysis, the association was still significant (Table 3). FSD was more prevalent among women with overweight $(\mathrm{p}<0.001)$, those with a low family monthly income $(\mathrm{p}=0.04)$, those in a negative couple relationship ( $\mathrm{p}$ $0.001)$, those with current depression $(\mathrm{p}<0.001)$, and those with a chronic medical disease $(\mathrm{p}=0.003)$.

Both the FSFI scores and the proportions of individuals with sexual disorders were similar between women undergoing CS and those having vaginal delivery for both individual domains and the full scale, as illustrated in Figure 1 and Figure 2. The FSFI scores and prevalence of FSD of each domain and full scale were extremely similar to the results shown in Table 1 for either cesarean or vaginal delivery.

\section{Discussion}

Our study showed that FSD is not associated with mode of delivery on either the full FSFI scale or in individual domains. However, low family monthly income, a negative couple relationship, current depression and chronic medical disease are

Table 1. FSFI scores and prevalence of FSD for individual domains and the full scale $(\mathrm{N}=$ 1354).

\begin{tabular}{ccc}
\hline & Score Median $(\mathrm{IQR})^{*}$ & Disorder N (\%) \\
\hline Desire & $3(2.4,3.6)$ & $911(67.2)$ \\
Arousal & $3.9(3.3,4.5)$ & $266(19.6)$ \\
Lubrication & $5.1(4.2,5.7)$ & $143(10.6)$ \\
Orgasm & $4.4(3.6,5.2)$ & $207(15.3)$ \\
Satisfaction & $4.8(4.0,5.6)$ & $214(15.8)$ \\
Pain & $6.0(4.8,6.0)$ & $142(10.5)$ \\
Full scale & $26.9(23.5,29.5)$ & $463(34.2)$ \\
\hline
\end{tabular}

*IQR: inter-quartile range 
Table 2. Characteristics of women according to FSD status $(\mathrm{N}=1354)$.

\begin{tabular}{|c|c|c|c|}
\hline & $\mathrm{FSD}(\mathrm{N}=463)$ & Non-FSD $(\mathrm{N}=891)$ & $P$ value \\
\hline $\mathrm{Age}^{\dagger}$ & $35(30.41)$ & $35(30.40)$ & 0.13 \\
\hline BMI & & & $0.004^{* *}$ \\
\hline$<18.5$ & $22(32.4)$ & $46(67.6)$ & \\
\hline $18.5-24.9$ & $353(35.5)$ & $640(64.5)$ & \\
\hline $25-29.9$ & $69(26.7)$ & $189(73.3)$ & \\
\hline$\geq 30$ & $19(54.3)$ & $16(45.7)$ & \\
\hline Education & & & 0.66 \\
\hline middle school or lower & $27(35.1)$ & $50(64.9)$ & \\
\hline high school or technical & $80(31.7)$ & $172(68.3)$ & \\
\hline college & $356(34.7)$ & $669(65.3)$ & \\
\hline Family monthly income & & & $0.006^{* *}$ \\
\hline$<900$ USD & $173(39.4)$ & $266(60.6)$ & \\
\hline$\geq 900$ USD & $290(31.7)$ & $625(68.3)$ & \\
\hline Marital status & & & 0.17 \\
\hline married & $454(34.0)$ & $883(66.0)$ & \\
\hline unmarried & $9(52.9)$ & $8(47.1)$ & \\
\hline Relationship with partner & & & $<0.001^{\star * *}$ \\
\hline negative & $144(56.5)$ & $111(43.5)$ & \\
\hline positive & $314(28.7)$ & $779(71.3)$ & \\
\hline Current depression & & & $<0.001^{* * *}$ \\
\hline no & $355(31.7)$ & $766(68.3)$ & \\
\hline yes & $108(46.8)$ & $123(53.2)$ & \\
\hline Chronic medical disease & & & $0.001^{* *}$ \\
\hline no & $419(33.1)$ & $848(66.9)$ & \\
\hline yes & $44(50.6)$ & $43(49.4)$ & \\
\hline Mode of delivery & & & 0.79 \\
\hline vaginal delivery & $220(34.6)$ & $415(65.4)$ & \\
\hline cesarean section & $243(33.8)$ & $476(66.2)$ & \\
\hline
\end{tabular}

trepresented by median (IQR); others represented by frequency (\%)

Table 3. Characteristics related to FSD based on logistic regression $(\mathrm{N}=1354)$.

\begin{tabular}{|c|c|c|c|c|}
\hline & $\begin{array}{c}\text { Crude OR } \\
(95 \% \mathrm{CI})^{\dagger}\end{array}$ & $\begin{array}{l}\text { Adjusted OR } \\
\quad(95 \% \mathrm{CI})\end{array}$ & $\begin{array}{c}\text { P value } \\
\text { (Wald's test) }\end{array}$ & $\begin{array}{c}\text { P value } \\
(\text { LR test })^{\ddagger}\end{array}$ \\
\hline Negative couple relationship & $3.21(2.43,4.25)$ & $3.04(2.28,4.05)$ & $<0.001$ & $<0.001^{\star * *}$ \\
\hline BMI (ref. = “18.5 - 24.9”) & & & & $<0.001^{\star * *}$ \\
\hline$<18.5$ & $0.87(0.52,1.47)$ & $0.82(0.47,1.41)$ & 0.47 & \\
\hline $25-29.9$ & $0.66(0.48,0.89)$ & $0.55(0.40,0.76)$ & $<0.001$ & \\
\hline$\geq 30$ & $2.17(1.10,4.27)$ & $1.7(0.83,3.49)$ & 0.15 & \\
\hline Low family monthly income & $1.37(1.08,1.74)$ & $1.31(1.02,1.68)$ & 0.04 & $0.04^{*}$ \\
\hline Having current depression & $1.90(1.42,2.53)$ & $1.71(1.26,2.31)$ & $<0.001$ & $<0.001^{\star * *}$ \\
\hline Having a medical disease & $2.09(1.35,3.23)$ & $2.06(1.28,3.31)$ & 0.003 & $0.003^{\star \star}$ \\
\hline
\end{tabular}

${ }^{\dagger} 95 \%$ confidence interval; ${ }^{\ddagger}$ likelihood ratio test. 




Figure 1. FSFI scores by mode of delivery.

\section{Prevalence of FSD by mode of delivery}

Full scale
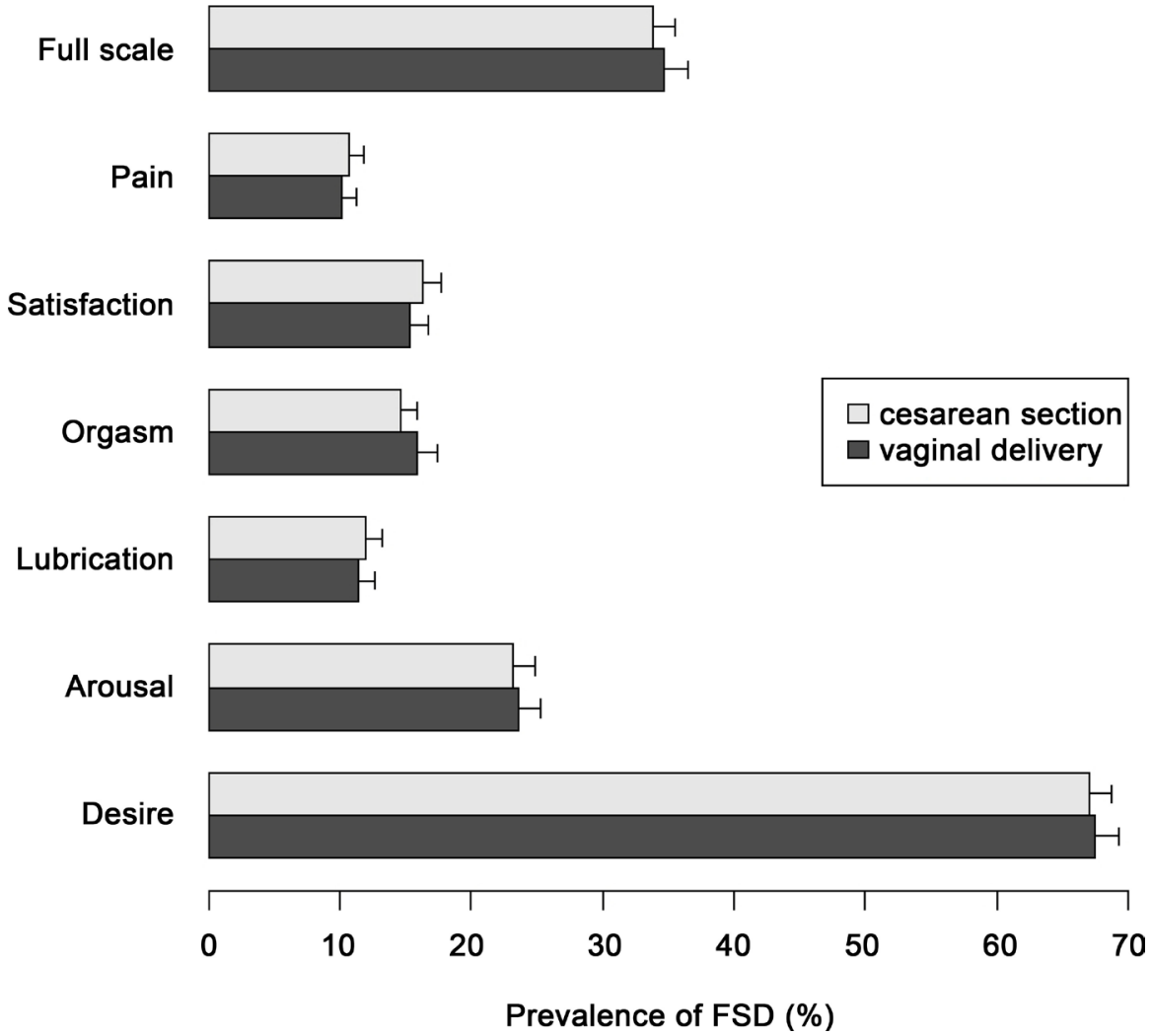

Figure 2. Prevalence of all FSD domains by mode of delivery. 
risk factors for FSD among parous women. The proportion of women with FSD in our study was slightly higher than that reported for reproductive-aged women in the US [3]. This discrepancy may be due to differences in study populations, as we included only parous women. Moreover, the desire domain was uniquely high compared to other sexual function domains, which may have resulted from shyness in discussing sexual desire due to Chinese cultural norms. The total FSFI score was comparable between our study and Lurie's, who reported a score of 27.7 at 24 weeks postpartum [8].

Compared to CS, vaginal delivery is perceived as more likely to affect female sexual function because the pelvic floor and perineum are stretched, and the risk of an episiotomy or assisted vaginal delivery (AVD) is increased [5]. However, our study showed no significant association between female sexual health and mode of delivery. Previous studies investigating sexual function among primiparous women within 6 months postpartum using the FSFI also found no significant differences between mode of delivery and sexual functioning in any domain [7] [8]. Cai et al. also reported that vaginal birth had no significant effect on sexual satisfaction or sexual function as indicated by the FSFI, although intravaginal pressure was lower in the vaginal-delivery group than the CS-delivery group after giving birth [9]. It should be noted that the above-referenced studies used only a short period of follow-up after delivery and had small sample sizes.

As sexual health encompasses physical, emotional, and mental well-being and involves both men and women [1], an association between female sexual function and the couple relationship is conceivable. Negative feelings about the couple relationship held by women led to a threefold higher risk of FSD in the present study. It has been reported that a woman's sexuality is highly affected by her perception of partnership quality [17] [18]. Low family monthly income was another identified risk factor for FSD in this study. It has previously been shown that social class and education are associated with female sexual function [19]. Gungor et al. also demonstrated that a low female education level was adversely associated with female sexuality [20]. The impact of socioeconomic factors on sexual function requires substantially more research.

It is interesting that sexual function was higher among overweight women compared to women of normal weight in our study. Gungor et al. also reported that overweight/obese women were more likely to report higher sexual satisfaction [20]. However, according to another recent study examining the relationship between BMI and sexual health, no significant association exists between BMI and sexual function, although BMI affected sexual satisfaction and desire, and pain dysfunction was found at the lowest frequency among overweight women [21]. It is not certain whether body self-acceptance underlies the effect of BMI on female sexual function; therefore, the relationship between BMI and sexual function should be further investigated [18].

Based on a recent review, conditions such as diabetes, heart disease, urinary tract disorders, and chronic illness are significant risk factors for sexual dysfunction in both women and men. Psychosocial factors such as depression and an- 
xiety are clearly risk factors for sexual dysfunction as well [22]. Therefore, there was an expectation in the present study that women with diseases or depression would show FSD. Thus, women with sexual dysfunction should be offered both medical and psychosocial evaluation and treatment if necessary.

Our study recruited only primiparous women; as such, the possible confounding effect of parity and mixed mode of delivery was eliminated. We also utilized a large sample size and extended duration after birth to enable assessments of the long-term effects of mode of delivery on sexual health. Moreover, a validated FSFI questionnaire was used to investigate female sexual function, which made our findings comparable with other studies. Some limitations of this study were noted. First, the name list and workplaces of the women were not available, and thus, the response rate could not be determined. The women who did not participate may have had unique characteristics compared with those who did participate. Second, a temporal and causal relationship between mode of delivery and most health problems was difficult to identify due to the crosssectional study design. However, we emphasized the sexual problems after childbirth and adopted the standard FSFI and EPDS questionnaires.

In conclusion, there were minimal differences in female sexual function scores and FSD prevalence between women undergoing CS versus vaginal delivery. The socioeconomic, physical, and psychological factors leading to FSD should be further investigated. Based on our findings, the prevention of FSD should not be the sole reason for performing CS.

\section{Acknowledgements}

The Letten Foundation (Oslo, Norway) provided financial support for the present study. We appreciate all the staffs for helping us to recruit the participants in this study.

\section{Disclosure}

All the authors are independent of funders. We certify that we have participated sufficiently in the design, data collection and analysis of the data as well as the writing of manuscript. The authors declare no competing interests.

\section{References}

[1] World Health Organization (2015) Sexual Health, Human Rights and the Law. http://www.who.int/reproductivehealth/publications/sexual_health/sexual-health-h uman-rights-law/en/

[2] Basson, R., Berman, J., Burnett, A., et al. (2000) Report of the International Consensus Development Conference on Female Sexual Dysfunction: Definitions and Classifications. The Journal of Urology, 163, 888-893. https://doi.org/10.1016/S0022-5347(05)67828-7

[3] Shifren, J.L., Monz, B.U., Russo, P.A., Segreti, A. and Johannes, C.B. (2008) Sexual Problems and Distress in United States Women: Prevalence and Correlates. Obstetrics and Gynecology, 112, 970-978.

https://doi.org/10.1097/AOG.0b013e3181898cdb 
[4] Khajehei, M., Doherty, M., Tilley, P.J. and Sauer, K. (2015) Prevalence and Risk Factors of Sexual Dysfunction in Postpartum Australian Women. The Journal of Sexual Medicine, 12, 1415-1426. https://doi.org/10.1111/jsm.12901

[5] Klein, M.C. (2012) Cesarean Section on Maternal Request: A Societal and Professional Failure and Symptom of a Much Larger Problem. Birth, 39, 305-310. https://doi.org/10.1111/birt.12006

[6] Rosen, R., Brown, C., Heiman, J., et al. (2000) The Female Sexual Function Index (FSFI): A Multidimensional Self-Report Instrument for the Assessment of Female Sexual Function. Journal of Sex \& Marital Therapy, 26, 191-208. https://doi.org/10.1080/009262300278597

[7] Dabiri, F., Yabandeh, A.P., Shahi, A., Kamjoo, A. and Teshnizi, S.H. (2014) The Effect of Mode of Delivery on Postpartum Sexual Functioning in Primiparous Women. Oman Medical Journal, 29, 276-279. https://doi.org/10.5001/omj.2014.72

[8] Lurie, S., Aizenberg, M., Sulema, V., et al. (2013) Sexual Function after Childbirth by the Mode of Delivery: A Prospective Study. Archives of Gynecology and Obstetrics, 288, 785-792. https://doi.org/10.1007/s00404-013-2846-4

[9] Cai, L., Zhang, B., Lin, H., Xing, W. and Chen, J. (2014) Does Vaginal Delivery Affect Postnatal Coitus? International Journal of Impotence Research, 26, 24-27. https://doi.org/10.1038/ijir.2013.25

[10] Baksu, B., Davas, I., Agar, E., Akyol, A. and Varolan, A. (2007) The Effect of Mode of Delivery on Postpartum Sexual Functioning in Primiparous Women. International Urogynecology Journal and Pelvic Floor Dysfunction, 18, 401-406. https://doi.org/10.1007/s00192-006-0156-0

[11] Song, M., Ishii, H., Toda, M., et al. (2014) Association between Sexual Health and Delivery Mode. Sexual Medicine, 2, 153-158. https://doi.org/10.1002/sm2.46

[12] Li, W.Y., Liabsuetrakul, T., Stray-Pedersen, B., Li, Y.J., Guo, L.J. and Qin, W.Z. (2014) The Effects of Mode of Delivery and Time Since Birth on Chronic Pelvic Pain and Health-Related Quality of Life. International Journal of Gynaecology and Obstetrics: The Official Organ of the International Federation of Gynaecology and Obstetrics, 124, 139-142. https://doi.org/10.1016/j.ijgo.2013.07.029

[13] Oksuz, E. and Malhan, S. (2006) Prevalence and Risk Factors for Female Sexual Dysfunction in Turkish Women. The Journal of Urology, 175, 654-658. https://doi.org/10.1016/S0022-5347(05)00149-7

[14] Choo, V. (2002) WHO Reassesses Appropriate Body-Mass Index for Asian Populations. Lancet, 20, 235. https://doi.org/10.1016/S0140-6736(02)09512-0

[15] National Bureau of Statistics of China (2012) Per Capita Annual Income of Urban Households by Sources and Region: China Statistic Yearbook 2012. http://www.stats.gov.cn/tjsj/ndsj/2012/indexeh.htm

[16] Guo, X.J. (2007) Study on the Efficacy of the Edinburgh Postnatal Depression Scale in Parturients of Chengdu. Master Thesis, Nursing, Sichuan University, Nursing.

[17] Maseroli, E., Fanni, E., Mannucci, E., et al. (2016) Which Are the Male Factors Associated with Female Sexual Dysfunction (FSD)? Andrology, 4, 911-920. https://doi.org/10.1111/andr.12224

[18] Wallwiener, S., Strohmaier, J., Wallwiener, L.M., et al. (2016) Sexual Function Is Correlated with Body Image and Partnership Quality in Female University Students. The Journal of Sexual Medicine, 13, 1530-1538. https://doi.org/10.1016/j.jsxm.2016.07.020

[19] Aslan, E. and Fynes, M. (2008) Female Sexual Dysfunction. International Urogyne- 
cology Journal, 19, 293-305. https://doi.org/10.1007/s00192-007-0436-3

[20] Gungor, S., Baser, I., Ceyhan, S., Karasahin, E. and Acikel, C.H. (2007) Mode of Delivery and Subsequent Long-Term Sexual Function of Primiparous Women. International Journal of Impotence Research, 19, 358-365.

https://doi.org/10.1038/sj.ijir.3901546

[21] Rabiepoor, S., Khalkhali, H.R. and Sadeghi, E. (2016) What Kind of Sexual Dysfunction Is Most Common among Overweight and Obese Women in Reproductive Age? International Journal of Impotence Research, 29, 61-64. https://doi.org/10.1038/ijir.2016.46

[22] McCabe, M.P., Sharlip, I.D., Lewis, R., et al. (2016) Risk Factors for Sexual Dysfunction among Women and Men: A Consensus Statement from the Fourth International Consultation on Sexual Medicine 2015. The Journal of Sexual Medicine, 13, 153-167. https://doi.org/10.1016/j.jsxm.2015.12.015 